\title{
Indicators for the Global Compact on Refugees
}

\author{
Geoff Gilbert*
}

One of the guiding principles of the Global Compact on Refugees (GCR) is 'to operationalize the principles of burden- and responsibilitysharing to better protect and assist refugees and support host countries and communities' (para 5). Success will be measured by indicators to be developed ahead of the first Global Refugee Forum in 2019 (which will take stock of progress to date) (paras 102-03). This short article considers the kinds of indicators that might be appropriate to measure compliance and implementation.

\section{Indicating Compliance with a Non-Binding Document}

The Global Compact on Refugees (GCR) expressly provides in paragraph 4 that it is not legally binding. ${ }^{1}$ Paragraph 5 then sets out that:

The global compact emanates from fundamental principles of humanity and international solidarity, and seeks to operationalize the principles of burden- and responsibilitysharing to better protect and assist refugees and support host countries and communities.

\footnotetext{
* Professor of International Human Rights and Humanitarian Law, University of Essex. This paper has benefitted from a UK Research Council ESRC Impact Acceleration Award that allowed the author to be seconded to UNHCR from September 2017-July 2018, during which period he attended the Thematic Discussions on the Comprehensive Refugee Response Framework and the Formal Consultations on the Global Compact on Refugees. The author is also grateful to Judith Bueno de Mesquita, Paul Hunt, and Carmel Williams, colleagues at the School of Law and Human Rights Centre at the University of Essex, and to Vyaj Lovejoy (LLM candidate 2016-18) with whom he discussed some of these ideas while providing advice on her dissertation. Needless to add, the views expressed and any errors are the author's alone.

${ }^{1}$ However, the paragraph goes on to provide: 'Yet it represents the political will and ambition of the international community as a whole for strengthened cooperation and solidarity with refugees and affected host countries. It will be operationalized through voluntary contributions to achieve collective outcomes and progress towards its objectives, set out in para 7 below. These contributions will be determined by each State and relevant stakeholder, taking into account their national realities, capacities and levels of development, and respecting national policies and priorities.'
} 
Better protection and assistance to refugees runs parallel with more equitable and predictable burden- and responsibility-sharing by the international community. ${ }^{2}$ The conundrum of a non-binding document that is based on a commitment to providing 'concrete contributions ... based on the principle of burden- and responsibility-sharing' (para 49) is beyond the scope of this piece, ${ }^{3}$ but indicators for compliance need to be understood as a practical consequence thereof. While refugee protection in the post-war era has been an international obligation since 1951, guarantees to communities hosting refugees, and more predictable and equitable burden- and responsibility-sharing by the international community as a whole, are not expressly laid down by international law. ${ }^{4}$ As provided in paragraph 1 of the GCR, '[r]efugees and host communities should not be left behind' - a clear nod to the Sustainable Development Goals, which utilize indicators to measure compliance and progress towards their achievement.

\section{Better protection and assistance to refugees and host communities}

While the GCR is non-binding, it is 'grounded in the international refugee protection regime' and 'is guided by relevant international human rights instruments' (para 5). Thus, at one level there already exists a range of indicators against which to measure compliance and implementation: for instance, is the right to education being met, and

\footnotetext{
${ }^{2}$ See GCR paras $1,3,7,15,48$, and 101 . All of this needs to be set in the broader context of the Secretary-General's Triple Nexus of Humanitarian-DevelopmentPeace that is encapsulated in the 2017 New Way of Working, OCHA https://www.unocha.org/sites/unocha/files/NWOW\%20Booklet\%201ow\%20res.002 0.pdf; see also, ICVA briefing paper, Navigating the Nexus, https://reliefweb.int/sites/reliefweb.int/files/resources/ICVA_Nexus_briefing_paper \%20\%28Low\%20Res\%29.pdf. See also, ICRC BlogPost by G. Carbonnier, 'Revisiting the nexus: Numbers, principles and the issue of social change', 4 October 2018, http://blogs.icrc.org/law-and-policy/2018/10/04/revisitingnexu...ebc66b-57ead84e97-9072701\&mc cid=57ead84e97\&mc eid=195aac4589.

${ }^{3}$ The author is currently working on such a paper for a special issue of International Migration on the two global compacts in 2019.

${ }^{4}$ That said, article 1(3) of the UN Charter provides for international cooperation "in solving international problems ... of a humanitarian character", and the fourth preambular paragraph of the Refugee Convention provides: 'Considering that the grant of asylum may place unduly heavy burdens on certain countries, and that a satisfactory solution of a problem of which the United Nations has recognized the international scope and nature cannot therefore be achieved without international cooperation'. Thus, the fundamental principle of burden- and responsibility-sharing is set out in extant treaty obligations.
} 
can refugees exercise the right to work? Moreover, with respect to equitable burden- and responsibility-sharing, one could even have regard to article 2(1) of the International Covenant on Economic, Social and Cultural Rights (ICESCR) which calls on States parties 'to take steps, individually and through international assistance and cooperation, especially economic and technical, to the maximum of its available resources, with a view to achieving progressively the full realization of the rights recognized in the present Covenant' (emphasis added). While the GCR is non-binding, it cannot be wholly divorced from a series of pre-existing international obligations by which States are bound. That said, however, not all States are parties to all the relevant treaties, and even where they are, the rights may be restricted more than one would want in terms of providing better protection and assistance to refugees. ${ }^{5}$

3. Indicators for enhanced protection and for predictable and equitable burden- and responsibility-sharing

As for predictable and equitable burden- and responsibility-sharing, there is a total lack of detailed obligations by which to assess its effective operationalization. It is at this point that the use of indicators by the international community to assess the implementation of the GCR is essential if it is to be more than just another international document exhorting better practice for the future. As set out in paragraph 102 of the GCR, measuring success is to be assessed by reference to the objectives laid down in paragraph $7,{ }^{6}$ and indicators are to be developed in relation to each objective before the first Global Refugee Forum in December 2019.

Indicators vis-à-vis refugee protection and assistance and the situation of host communities may be related to existing international human rights law standards, but the same cannot be said with respect to equitable and predictable burden- and responsibility-sharing because

\footnotetext{
${ }^{5}$ Article 13.2(a) ICESCR only [why only? - see Highlighted text] guarantees free primary education to all - free secondary education and beyond is part of what states are progressively trying to fulfil. See also, Article $28 \mathrm{UN}$ Convention on the Rights of the Child, UNGA res. 44/25, annex, 44 UNGAOR Supp. (No. 49) at 167, U.N. Doc. A/44/49 (1989).

${ }^{6}$ These are to: '(i) ease pressures on host countries; (ii) enhance refugee selfreliance; (iii) expand access to third country solutions; and (iv) support conditions in countries of origin for return in safety and dignity.'
} 
these indicators, to a certain extent, establish tools for measuring how the international community as a whole supports countries of asylum, not just the hosting populations therein. Moreover, the creation of indicators of the sort proposed for the GCR cannot simply draw on existing models because the context is unique. Indicators only have value if designed to meet the specific commitments set out in the GCR.

The indicators are to assess the progress towards achievement of the four objectives in Paragraph 7 GCR.

7. ... to: (i) ease pressures on host countries; (ii) enhance refugee self-reliance; (iii) expand access to third country solutions; and (iv) support conditions in countries of origin for return in safety and dignity. The global compact will seek to achieve these four interlinked and interdependent objectives through the mobilization of political will, a broadened base of support, and arrangements that facilitate more equitable, sustained and predictable contributions among States and other relevant stakeholders.

As Paragraph 5 has made clear, the GCR "emanates from fundamental principles of humanity and international solidarity, and seeks to operationalize the principles of burden- and responsibility-sharing to better protect and assist refugees and support host countries and communities" (emphasis added). Thus, in interpreting the four objectives, one has regard to the fundamental principles of the GCR of enhanced protection and assistance and fairer and more equitable burden- and responsibility-sharing.

Even though there are pre-existing rights relating to protection, this does not mean that the indicators will be easy to draft or that they will lead to the enhancement of those rights. ${ }^{7}$ The experience with the Millennium Development Goals reveals that there is no guaranteed improvement in rights simply because there are indicators. ${ }^{8}$ While the development of the SDGs learnt from and built on this experience, ${ }^{9}$

\footnotetext{
${ }^{7}$ See generally, OHCHR, 'Human Rights Indicators: A Guide to Measurement and Implementation,' [2012] United Nations, UN Doc. HR/PUB/12/5, 21

${ }^{8}$ See S. Fukuda-Parr, AE Yamin and J. Greenstein, 'The Power of Numbers: A Critical Review of Millennium Development Goal Targets for Human Development and Human Rights', 15 Journal of Human Development and Capabilities: A MultiDisciplinary Journal for People-Centered Development, 105 (2014).

${ }^{9}$ The SDGs were agreed in 2015, but the indicators were only finalised in July 2017

- UNGA res 71/313, 6 July 2017.
} 
indicators necessarily make States focus on statistics, not necessarily on protection for the sake of protection. ${ }^{10}$ Furthermore, there is no necessary correlation between the statistics that are collected and respect for, protection of, and fulfilment of rights. As Williams and Hunt have made clear, the data relating to the SDG indicators do not correlate to all elements of specific rights and there may not be sufficient disaggregation. ${ }^{11}$

When it comes to indicators for more predictable and equitable burdenand responsibility-sharing, although there may be a much more limited legal framework underpinning it, that does not mean that a rights-based approach cannot be applied (especially since paragraph 5 of the GCR refers expressly to international human rights law). As regards some aspects of burden- and responsibility-sharing, there is clearly a direct correlation. For instance, as noted above, article 2(1) of the ICESCR calls on States to undertake 'through international assistance and cooperation, especially economic and technical' to fully realize the rights in that treaty, some of which directly pertain to the GCR. While that provision provides little detail to assist in formulating indicators, it does uphold the idea that a rights-based approach should be part of the process for establishing indicators for burden- and responsibilitysharing.

That said, the indicators for burden- and responsibility-sharing are as much about obligations between States as they are about protecting refugees and host communities, and finding durable and sustainable solutions to respond to displacement. The lack of a precise, pre-existing legal framework makes the establishment of detailed indicators, underpinned by robust statistics, even more important - and this may take time to develop. Relevant datasets may not exist, and even where data has been gathered for different purposes, it may not be directly applicable - for example, the number of refugees may not have been

\footnotetext{
${ }^{10}$ E. Díaz-Martínez and ED Gibbons 'The Questionable Power of the Millennium Development Goal to Reduce Child Mortality', 15 Journal of Human Development and Capabilities: A Multi-Disciplinary Journal for People-Centered Development 203 (2014).

${ }^{11}$ C. Williams and P. Hunt, 'Neglecting human rights: accountability, data and Sustainable Development Goal 3', 21 The International Journal of Human Rights 1, 11-17 (2017). See also, SLM Davis, 'The uncounted: politics of data and visibility in global health', 21 The International Journal of Human Rights 1144 (2017).
} 
disaggregated. ${ }^{12}$ The speed at which events change during displacement adds yet another layer of complexity to data collection and analysis. And, ultimately, in measuring burden- and responsibility-sharing there is an element of comparing chalk and cheese: how much of a contribution is a State making which takes in 100,000 refugees, as against a State that contributes US $\$ 40$ million to aid budgets (and does it matter if it is humanitarian or development aid?), or one that permanently resettles 1500 refugees, or even contributes 1000 troops to a peacekeeping mission for six months? And can one subtract from contributions, however measured and valued, the amount a State makes from the sales of arms and armaments that fuelled the conflict that has caused the refugee flow (to paraphrase UNHCR)? Establishing indicators is essential, but it will take time and experience to ensure that they properly reflect the complex reality of refugee protection.

\section{Conclusion}

The GCR represents a new departure in the protection of refugees, especially in recognizing the cost to States that host large numbers of them. Like any new departure, the practical implications of operationalizing a non-binding document - which nevertheless reflects States' political commitment to provide concrete contributions to burden- and responsibility-sharing by the international community as a whole - will take time to resolve. However, indicators are an essential step in ensuring proper burden- and responsibility-sharing through international cooperation.

\footnotetext{
${ }^{12}$ See M. Green, 'What we talk about when we talk about Indicators: Current Approaches to Human Rights Measurement' 23 Human Rights Quarterly 1084 at 1085 (2001). See also, Williams and Hunt and Davis, both above note 11. [Jean, I have checked ICESCR and GCR references but not others.]
} 